1 Saw Swee Hock School of Public Health, National University of Singapore, Singapore

2 Johns Hopkins University Bloomberg School of Public Health, US

3 Institute of Health Policy, Management and Evaluation, University of Toronto, Canada

${ }^{4}$ Department of Global Health and Development, London School of Hygiene and Tropical Medicine, UK

5 School of Public Health, Boston University, US

6 Berlin Institute of Global Health

7 Independent Panel for Pandemic Preparedness and Response Secretariat

Correspondence to: M M J Tan melisatan@nus.edu.sg Cite this as: $B M J$ 2021;375:e067512 http://dx.doi.org/10.1136/bmi-2021-067512 Published: 29 November 2021

COVID-19 PREPAREDNESS AND RESPONSE: IMPLICATIONS FOR FUTURE PANDEMICS

\title{
Assessing the role of qualitative factors in pandemic responses
}

\begin{abstract}
Melisa Tan and colleagues argue that assessments of national pandemic preparedness and response capacities should be extended to include social factors, leadership, and use of evidence
\end{abstract}

Melisa Mei Jin Tan, ${ }^{1}$ Rachel Neill, ${ }^{2}$ Victoria Haldane, ${ }^{3}$ Anne-Sophie Jung, ${ }^{4}$ Chuan De Foo, ${ }^{1}$ See Mieng Tan, Pami Shrestha, ${ }^{1}$ Monica Verma, ${ }^{1}$ Mathias Bonk, ${ }^{6,7}$ Salma M Abdalla, ${ }^{5,7}$ Helena Legido-Quigley, ${ }^{1,4}$,

The covid-19 pandemic has emphasised shortcomings in global systems for measuring the ability of countries to respond rapidly to emerging infectious disease threats. Existing monitoring and evaluation processes-including the Global Health Security Index, the Epidemic Preparedness Index, and the Joint External Evaluation-have highlighted a lack of preparedness across countries, particularly among low and middle income countries. Currently, these measurement frameworks emphasise structural aspects of the health system, including capacity, laboratory infrastructure, financing, surveillance, and emergency response operations, but fail to account for critical dimensions such as governance, cooperation, and collaboration, which are difficult to quantify. ${ }^{12}$

During the covid-19 pandemic these qualities have shaped the ability of countries to prepare proactively, respond promptly, and recover equitably while protecting the health and wellbeing of communities. Overlooking these considerations has biased existing frameworks towards high income countries, failed to account for socioeconomic inequalities, and underestimated the role of leadership and societal engagement in translating policy planning into implementation. ${ }^{12}$ The preparedness indicators therefore do not accurately reflect the ability of countries to respond to infectious hazards.

After consulting experts on covid-19 working across academia, government, the private sector, and not-for-profit sector, and carrying out desk reviews (see supplementary data on bmj.com for details), ${ }^{1}$ and building on recent work that highlighted limitations of the Global Health Security Index, we outline six factors that have shaped national responses to covid-19 (box 1). Such "soft" factors must be incorporated into future national and global measurement frameworks to advance a holistic, equitable, and truly preventive approach to evaluating pandemic preparedness.

Box 1: Essential components in shaping pandemic preparedness and response

- National governance and leadership to guide timely responses

- Incorporating scientific advice and evidence into decision making

- Pre-existing community engagement structures towards greater trust
- Role of social norms and cohesion in shaping national responses

- Technosciences, social factors, and inequalities

- Cross border cooperation to enhance domestic preparedness and response

\section{National leadership and governance}

The covid-19 pandemic has emphasised how governance can determine a country's performance in responding to outbreaks. The experts identified integrity, humility, open mindedness, transparency, and empathy as hallmarks of good governance during public health emergencies. As such, the ability of decision makers and leaders to take the threat posed by the pandemic seriously is crucial, including putting the wellbeing and safety of populations before personal interests. One factor is the willingness of ruling parties or leaders to collaborate with other political parties to establish consensus, rather than fracture governments. Fragmented governments were seen to be navigating political opposition and dissent, rather than pooling much needed resources. This was often evident in countries with upcoming elections, where covid-19 was used as leverage for political gain.

In contrast, more successful governance was evidence informed rather than politically motivated. Good governance and leadership that prioritises the needs of communities is further characterised by open, multilevel communication channels within and beyond government structures, industry players, and communities. High performing countries have implemented whole-of-government approaches, working across multiple levels of government, and consulting validated scientific evidence while concomitantly engaging communities to tailor a national response. Clear and effective coordination based on collaboration was considered key for successful responses.

Collaborative governance and sensible leadership can influence countries' performance in the covid-19 response. Indeed, the experts pointed towards the failures of leaders and behaviours that were primarily concerned with electoral and political advantage, even when coming at the cost of wellbeing or human rights. Countries with poor, uncoordinated, diffused, or delayed responses continued to underperform in their response, in some cases driven by pervasive scepticism from leadership about the extent and 
seriousness of the pandemic. Yet, despite the growing recognition of leadership and governance as the cornerstone of responses, these aspects are rarely directly assessed in existing measurement frameworks.

\section{Evidence based decision making}

Although capacity to generate and use scientific advice is a recognised component of pandemic preparedness and response, willingness to incorporate that advice is equally critical.

Measurement dimensions focused on capacity tend to be favourable to high income countries, but covid-19 has highlighted that willingness to incorporate scientific advice in decision making and communicate it to the public is variable, regardless of a country's income or scientific capacities.

These challenges were exacerbated by evolving scientific evidence and difficulties translating emerging scientific evidence to policy actions. Some countries had the scientific resources and expertise to back evidence based policy recommendations but faced challenges in garnering political support. Despite domestic research groups and scientists offering expert advice and precautionary warnings, leaders in some countries politicised the pandemic by placing their political agendas above science. As a result, risk communication to communities was undermined by political leaders whose opinions over-rode expert advice.

On the other hand, some leaders took guidance from credible sources and formed expert committees or working groups to guide the pandemic response. Countries in which politicians acknowledged and incorporated scientific evidence into policy responses generally performed better. In Uruguay, which did well in the first year of pandemic, having collaborative scientific committees with direct reporting lines to the presidential level and making information available publicly, contributed to decision making that was based on evidence and gaining the trust of the population. This highlights the need to develop trusted communication through effective knowledge translation.

\section{Pre-existing community engagement structures}

A functioning community engagement structure is critical for an effective response to disease outbreaks. Countries that had health systems with strong ties to communities could respond quickly and effectively to outbreaks. Embedding community level healthcare in the response strategy depends on longstanding engagement with the communities involved. In Liberia, Thailand, and Vietnam, community health workers were rapidly trained, equipped, and deployed to respond at the community level while being closely linked with healthcare facilities. Training included identifying suspected cases, surveillance, contact tracing, referral protocols, and supporting patients in home isolation. In many of these settings, community health workers were part of the healthcare system before covid-19, highlighting the importance of sustained efforts to engage communities, not only during emergencies.

To strengthen community engagement, it is important to build and maintain trust, improve confidence in the government, and instil a sense of civic mindedness and self-responsibility. Most settings with high levels of trust in government have had positive outcomes. However, some were successful despite low trust. In Hong Kong, for example, a lack of trust in the government led the population to self-impose measures that were stricter than those proposed by the government to tackle covid-19. Established community networks within Hong Kong and the accompanying trust in these networks led to adoption of preventive measures before they were introduced by the government. ${ }^{3}$
Importantly, the pandemic has shown the value of active community engagement in designing as well as implementing interventions, an approach used in many low and middle income countries before the pandemic. Much can be learnt from the experiences of low and middle income countries in co-producing knowledge and working with communities to find feasible and acceptable solutions for healthcare concerns. ${ }^{4}$ These considerations can be incorporated into existing measurement frameworks, reflecting a whole of society approach that connects public health infrastructure to community needs.

\section{Role of social norms and cohesion}

Countries with a more cohesive society and with a cultural norm of complying with authority performed better than countries with a more individualistic social outlook. Mask wearing in countries such as Japan and South Korea was already the norm when experiencing respiratory symptoms. ${ }^{3}$ Increasingly, mask wearing has also become part of pop culture and to an extent used as a fashion accessory in these countries. Such cultural acceptance of mask wearing greatly aided adherence to mandatory mask wearing policies.

Cohesion is also an important aspect of ensuring the community complies with measures. In countries that have succeeded in containing the virus, there is usually a sense of collectivism to act responsibly to protect their community; by contrast those that have relied on individual responsibility have struggled.

Singapore managed to suppress spikes in cases because of the population's overall trust in the government. Singapore's social fabric and the knowledge that the government had previously controlled severe acute respiratory syndrome (SARS) meant that people followed the measures without backlash during the first year of the pandemic. Furthermore, social connectedness and a sense of unity could be observed in countries where leaders listened to experts and shaped a culture of being ready to change course as soon as the conditions permitted, such as New Zealand and Australia. New Zealand's public service was agile enough to provide an infrastructure to mount a rapid and detailed technical response. These characteristics are not included in current evaluation frameworks but were critical in shaping the ability of governments to implement necessary public health measures and sustain them through multiple waves of infection.

\section{Technosciences, social factors, and inequalities}

The threats of the virus extend beyond individual and biological risks. The experts we interviewed emphasised that more attention needs to be paid to the interaction between biological and social structures by adopting a syndemic perspective. This demands consideration of how covid-19 and other diseases coexist within the same social environment. ${ }^{5}$ Understanding the social, built, and natural environments in which pandemics and chronic ill health arise and exacerbate inequities is crucial to strengthening pandemic preparedness and response efforts. During the pandemic, some countries prioritised tackling inequalities embedded in societies, while others were slow to recognise these as part of their response. ${ }^{6}$ For example, many countries enacted financial measures such as income supports, debt relief, and loan forgiveness to protect individuals and families from the effects of public policies to limit transmission of covid-19. As the accelerating effects of climate change and environmental degradation couple with migration, urbanisation, and increasing social and economic inequity, we must continue to pursue actions that tackle the ecological, political, commercial, and social determinants of health (box 2). ${ }^{30}$ 
Box 2: Examples of upstream actions to tackle ecological, political, commercial, and social determinants of health

\section{Measures to support individuals for accessing covid-19 treatments}

Affordable access to treatments can reduce barriers to healthcare services and speed up detection of covid-19. Countries such as Thailand, Fiji, New Zealand, and the UK ${ }^{7-10}$ have offered free testing for their citizens, while others, such as China, ${ }^{11}$ reimburse the costs. Thailand also made state quarantine available for anyone with a positive result.

Measures to provide economic support to businesses and individuals

Economic support is essential to assist businesses and individuals in their recovery from the pandemic. Many countries provided financial assistance to businesses and extended flexibility in loans and rental fees. ${ }^{12-16}$ For example:

- Argentina prohibited dismissals and suspensions of workers for 60 days without any justifiable reasons ${ }^{17}$

- Singapore waived rental fees and provided relief payments to taxi and private hire car operators. 18

\section{Political factors that shape the covid-19 responses}

The way political structures and governmental services are organised determines how organisations and individuals align their actions with requirements. Countries with federal governments or decentralised structure such as Germany and Sweden had to manage the outbreak by maintaining communication channels and agreeing on restriction measures between government levels. ${ }^{19} 20$

A further challenge was achieving consensus among politicians and scientists, who may have different perceptions about the virus, although countries such as Uruguay, Thailand, and Germany had groups of scientific experts in dedicated public health institutions or taskforces to guide policy directions. ${ }^{21-23}$

\section{Addressing the effect of health services on the environment}

Accelerating environmental degradation due to climate change is expanding the human-animal interface and risk of zoonotic diseases with pandemic potential. ${ }^{24} 25$ Paradoxically, the delivery of healthcare is a major contributor towards carbon emissions. ${ }^{26}$ While early in the pandemic modest reductions in emissions were seen because of movement controls, evidence on the use of medical supplies and healthcare points to increasing intensity of healthcare waste and energy consumption. ${ }^{2728}$ Health systems need to set ambitious decarbonisation goals, such as those set in the UK, to ensure the health of people and the planet. ${ }^{29}$

It is difficult to quantify these dimensions and define their causal relation, but they influence the speed at which countries slow community transmission. Several studies have noted the inadequacy of current indices to predict pandemic preparedness. ${ }^{31-33}$ The results can become subjective and difficult to compare across countries, and they do not include context specific elements that can be difficult to quantify. ${ }^{133}$

The use of standards and indicators as tools to make health and health programmes measurable has become an essential part of the study of structural power in global health and global

governance. ${ }^{34-39}$ The development of indicators will ultimately result in the definition of specific goals, setting of targets, and embedding obligations to achieve these goals, and this approach is widely used in vertical health interventions. Both the Global Health Security Index and universal health coverage take broader, more horizontal, approaches to health and wellbeing, incorporating aspects of equality and health systems. Yet, the Global Health Security Index also fails to recognise all aspects of a response and the intrinsic complexities of health and health systems. These may not be quantifiable.
The pandemic has highlighted once more that global public health policy is often driven towards a focus on technoscientific expertise as represented in the natural sciences. This is particularly visible in the type of scientific evidence that is valued, which scientists were asked to provide advice, and the general disciplinary composition of scientific expert groups. Scientific advisory panels often do not include social scientists or community advocacy groups and lack geographical and gender diversity. ${ }^{40}$

\section{Cross border cooperation}

Measurement frameworks prioritise national and subnational capacities. However, covid-19 has highlighted the inherent interconnectedness of response strategies and the variable ability and willingness of national governments to engage with regional and international bodies. Cross border cooperation is crucial to mounting an effective response at the global, regional, and national level (box 3). At the global level, international organisations called for cooperation and charted a course towards collective action. The World Health Organization exercised its convening power as a global health authority to gather scientific experts and high level policy makers through regional offices and pre-existing and newly formed standing committees or working groups. In theory, communication is bidirectional, with WHO receiving input from member states, although this occurred to varying degrees depending on country context.

Box 3: Examples of covid-19 related responses and measures at global, regional, and national level

\section{Global cooperation}

International partnerships can lead to rapid resource mobilisation during global health emergencies. The partnership between the WHO, the UN Foundation, and a global network of institutions led to the establishment of the COVID-Solidarity Response Fund, which serves as a conduit for donations from private individuals and organisations..$^{41} \mathrm{WHO}$ and its partners also launched the Solidarity trial in March 2020-an international clinical trial system that facilitates patient enrolment into a single randomised trial to accelerate investigation of potential treatments. ${ }^{42}$ Regional cooperation

-The EU set out to coordinate a common European response to covid-19. Examples of measures implemented included financing contracts to secure medicines, grant support to conduct clinical trials, purchase of over 20 million rapid antigen tests for member states, and providing around $€ 100 m$ to procure essential medical supplies. 43 The EU extended support to other countries in need of additional resources, including those in southern Africa, Latin America, and Southeast Asia. 44-46

-The Association of Southeast Asian Nations (ASEAN) held talks to strengthen regional capacities and shape knowledge exchange. The covid-19 ASEAN response fund was established to help member states procure medical supplies and equipment, 47 and an Emergency Operation Centre was set up to facilitate daily communication and sharing of epidemiological information through WhatsApp..$^{48}$ The region also launched the ASEAN BioDiaspora programme, which connects multiple datasets to allow real time assessment of the pandemic.

-The Africa Centres for Disease Control and Prevention (Africa CDC) increased testing capacities, established distribution hubs for medical supplies, and deployed one million community workers for contact tracing. 49 In January 2021, it announced that the African Union had secured 670 million doses of vaccines, which will help boost the vaccination rates in its member states. ${ }^{50}$

National cooperation

Mobilising funds for covid-19 related activities

To help developing countries cope with the pandemic, official donors had contributed foreign aid of $\$ 161.2 \mathrm{bn}$ in 2020 , up $3.5 \%$ from $2019 . .^{1}$ The US remains the leading overseas development aid donor but EU 
institutions increased their aid by $25.4 \%$ (in real terms) because of mobilising funds for covid-19.

Provision of medical supplies

Germany donated $\$ 1.18 \mathrm{~m}$ worth of medical equipment to Peru to support healthcare services for native communities in San Martin and Ucayali regions. ${ }^{52}$ It also sent medical staff and equipment to Portugal and India following surges in covid-19 cases. 5354 As one of the countries with a low burden of covid-19 cases, New Zealand has offered support to countries in need of medical supplies as well as rapid financial support to Pacific Island countries. 55

Regional networks and institutions proved increasingly important to drive effective pandemic responses, according to our experts.

Regional networks in Africa, the European Union, and Association of Southeast Asian Nations were offered as key examples of regional cooperation, including financing, resource procurement, technical support, and knowledge sharing. The African Union Covid-19 Solidarity Response Fund was launched to mitigate the social, economic, and humanitarian impact of covid-19 in all African countries. ${ }^{56}$

The experts acknowledged that bolstering countries' resources to fight the pandemic needs to be complemented by expanded knowledge of effective and sustainable response strategies. African countries that had experienced Ebola were better prepared. Both Singapore, which had dealt with SARS in 2003, and South Korea, affected by Middle East respiratory syndrome in 2015, already had healthcare and governance structures in place to keep the pandemic under control. Their experiences in responding to infectious disease outbreaks were subsequently touted as exemplars. However, most participants emphasised that while cross border collaboration and learning are crucial during pandemic preparedness and response, these were insufficient during the current pandemic.

Vaccination is essential to reduce the susceptibility to covid-19. Balancing the supply and demand of vaccines remains a daunting task, although global initiatives such as Covax are available to help. ${ }^{57}$ The current unequal distribution of vaccines is concerning, and greater donation of doses and manufacturing capacity are required. Another article in this series considers how to counter vaccine nationalism by incorporating rules and industrial policies to govern the collaboration between public and private sectors. ${ }^{58}$ Countries' participation in and contributions to cross border learning, data sharing, and coordination efforts contribute to an effective pandemic preparedness and response and should therefore be included in future measurement frameworks.

\section{Conclusion}

The covid-19 pandemic has demanded decisions be made under challenging circumstances. However, the choices available are not only limited by resources but shaped by existing models, governance structures, and social realities. The Global Health Security Index and the joint external evaluation tool have been used to estimate the resources needed for countries to prepare and sustain responses to large scale global infectious disease outbreaks. Yet these monitoring mechanisms have been constrained in practice by power dynamics, global inequalities, financing, and social ties. This restricted view hinders our ability to prevent outbreaks from becoming pandemics while biasing the global understanding of preparedness towards high income countries.

Moving forward, global health organisations and countries must draw on our diverse experiences responding to covid-19 to reimagine how we prepare for and respond collectively to ongoing and future threats to global health and wellbeing. A part of this reimagining requires a better assessment of national capacities to detect and react to outbreaks. Preparedness frameworks should, at minimum, include indicators that consider the broader societal aspects we highlight here. Novel frameworks must evaluate how leaders make decisions, communicate information, and facilitate responses across levels, both domestically and globally. This work will require an innovative and collaborative research agenda and the development of metrics capable of capturing this complexity while producing meaningful and comparable insights that leaders can act on (table 1).

\section{Table 1| Key considerations for evaluating pandemic responses}

\section{Consideration}

Cross border cooperation to enhance domestic preparedness and response

\section{Key research questions}

How can countries strengthen existing cross border cooperation structures to facilitate cooperation?

How can national rules and regulations be refined to permit cross border cooperation during health emergencies?

National governance and leadership to guide timely responses

What are the elements that can allow head of states and governments to lead effectively before, during, and after public health emergencies?

How can political systems be organised and strengthened to ensure that health emergencies are prioritised despite differing political ideologies?

Incorporating scientific advice and evidence into decision making

How can scientific evidence be better incorporated in national policy processes?

What processes are needed for effective communication between the scientific communities and decision makers?

Pre-existing community engagement structures towards greater trust

How can countries establish trust within communities?

What are the structures that can foster and encourage bi-directional communication between the community and decision makers?

How can the community be more involved in decision making processes and co-produce community friendly policies?

Role of social norms and cohesion in shaping national responses

How can decision makers gain a better understanding of the social norms in their community? What are the structures needed to facilitate social cohesion?

Intersection of biological and social factors with inequalities
How can decision makers incorporate issues relating to how biological and social factors interact with social inequalities in the policy process?

What are the structures (community and national) that can improve social conditions as part of national development?

How can socioeconomic inequalities be addressed more effectively? 
As the adage goes, "What gets measured, gets done.” To make this the last pandemic, we must shape a global measurement system centred around social values that guide people- leaders or otherwise-in making decisions responsibly and confidently to prepare for, respond to, and recover from public health emergencies.

\section{Key messages}

- The Global Health Security Index and the joint external evaluation tool had limited predictive value regarding individual countries' level of preparedness for covid-19

- Factors that are hard to quantify such as robust governance and leadership and evidence informed decision making have proved important

- Social values and contexts underpin pragmatic decision making processes and must be considered in evaluative efforts

- A syndemic perspective is useful to understand the social patterns of covid-19 and inequalities within society

- Pandemic preparedness frameworks that prioritise wellbeing over economic or political gains will require innovative and collaborative research to produce measurable indicators

Contributors and sources: This analysis was part of the work commissioned by the Independent Pane for Pandemic Preparedness and Response, which reviewed the national responses of 28 countries Data used for the analysis was collected through literature review of peer reviewed papers, policy documents, public reports, and articles that examined national and sub-national policy responses; semistructured interviews with country experts and national government written submission of selected countries about measures implemented to contain covid-19; and validation of country specific data by experts through written consultation and round table discussion. MT and HL-Q conceived and designed the manuscript. MT, RN, VH and $\mathrm{HL}-\mathrm{Q}$ drafted the manuscript with inputs from all authors. All authors contributed to revising the manuscript and approved the final version. $\mathrm{HL}-\mathrm{Q}$ is guarantor for the paper

Competing interests: We have read and understood BMJ policy on declaration of interestsand have no interests to declare. MB, SMA, and $\mathrm{HL}-\mathrm{Q}$ are members of the secretariat of the Independent Panel for Pandemic Preparedness and Response. The secretariat is independent.

Provenance and peer review: Commissioned; externally peer reviewed.

This collection of articles was proposed by The Independent Panel for Pandemic Preparedness and Response. Open access fees were funded by WHO and Singapore's National Medical Research Council (NMRC/CG/CO26/2017_NUHS). The BM/commissioned, peer reviewed, edited, and made the decision to publish these articles. Kamran Abbasi was the lead editor for The BMJ.

Baum F, Freeman T, Musolino C, etal. Explaining covid-19 performance: what factors might predict national responses?BMJ2021;372:n91. doi: 10.1136/bmj.n91 pmid: 33509924

2 Stowell D, Garfield R. How can we strengthen the joint external evaluation?BMJ Glob Health 2021;6:e004545. doi: 10.1136/bmigh-2020-004545 pmid: 34006517

3 Han E, Tan MMJ, Turk E, etal. Lessons learnt from easing COVID-19 restrictions: an analysis of countries and regions in Asia Pacific and Europe. Lancet 2020;396:1525-34. doi: 10.1016/S0140-6736(20)32007-9 pmid: 32979936

4 Marten R, El-Jardali F, Hafeez A, Hanefeld J, Leung GM, Ghaffar A. Co-producing the covid-19 response in Germany, Hong Kong, Lebanon, and Pakistan. BMJ2021;372:n243. doi: 10.1136/bmj.n243 pmid: 33593791

5 Bambra C, Riordan R, Ford J, Matthews F. The COVID-19 pandemic and health inequalities. J Epidemiol Community Health2020;74:964-8. doi: 10.1136/jech-2020-214401. pmid: 32535550

6 Tomson G, Causevic S, Ottersen OP, etal. Solidarity and universal preparedness for health after covid-19. BMJ 2021;372:n59. doi: 10.1136/bmj.n59. pmid: 33483301

7 Tangcharoensathien V, Bassett MT, Meng Q, Mills A. Are overwhelmed health systems an inevitable consequence of covid-19? Experiences from China, Thailand, and New York State. BMJ 2021;372:n83. doi: 10.1136/bmj.n83. pmid: 33483336

8 Ministry of Health \& Medical Services. Covid-19 tests available 2020. https://www.health.gov.fj/covid-19-tests-available/

9 New Zealand Government. Get tested for COVID-19. 2021. https://covid19. govt.nz/health-andwellbeing/covid-19-testing/get-tested-for-covid-19/.

10 Government of the United Kingdom. Get a free PCR test to check if you have coronavirus (COVID-19). 2021. https://www.gov.uk/get-coronavirus-test

11 National Healthcare Security Administration. The per-capita medical cost of patients with severe COVID-19 exceeds 150000 yuan, and will be reimbursed in accordance with regulations Beijing, China 2020. 2020. https://www.ccdi.gov.cn/yaowen/202004/t20200411_215163.html

12 Uruguay Presidency. Government measures to address the health emergency due to coronavirus (COVID-19) in labor matters. 2021. https://www.gub.uy/presidencia/politicas-y-gestion/medidasdel-gobierno-para-atender-emergencia-sanitaria-coronavirus-covid-19-2\#navegacion-contenido
13 National Emergency System. Situation report on coronavirus COVID-19 in Uruguay (03/19/2020). https://www.gub.uy/sistema-nacional-emergencias/comunicacion/comunicados/informe-situacionsobre-coronavirus-covid-19-uruguay-19032020

14 Saute R, Murrugarra E, Casal J, et al. COVID 19 in Mozambique: A team effort to ease the economic hardship on families. World Bank Blogs, 16 Sep 2020. https://blogs.worldbank.org/nasikiliza/covid19-mozambique-team-effort-ease-economic-hardship-families

15 New Zealand Government. Mortgage holiday and business finance support schemes to cushion COVID impacts 2020. https://www.beehive.govt.nz/release/mortgage-holiday-and-business-finance-support-schemes-cushion-covid-impacts

16 Ministry of Employment and Labor. Gov't launches additional economic relief measures for vulnerable groups affected by the covid-19 outbreak 2020. https://www.moel.go.kr/english/poli/poliNewsnews_view.jsp?idx=1559

17 Boletín Oficial de la República Argentina. Public Emergency - Decree 891/2020 DECNU-2020-891-APN-PTE - Prohibition of dismissals and suspensions. Extension, 2020.

18 Soh G. Cabbies and private-hire drivers to get more financial support with extension of covid-19 relief fund. The Straits Times 2021 Sep 24. https://www.straitstimes.com/singapore/community/cabbies-and-private-hire-drivers-to-get-more-financial-support-with-extension-of

19 Farr C. Germany's coronavirus response is a master class in science communication. CNBC 2020 Jul 21. https://www.cnbc.com/2020/07/21/germanys-coronavirus-response-masterful-sciencecommunication.html

20 OECD. How best to communicate on migration and integration in the context of COVID 19.2020 https://www.oecd.org/coronavirus/policy-responses/how-best-to-communicate-on-migrationand-integration-in-the-context-of-covid-19-813bddfb/ accessed 25 October 2021.

21 Ministry of Public Health. Ordinance No. 230/020 Create the Committee of Scientific Experts on Crisis Management, 2020. https://www.gub.uy/ministerio-salud-publica/institucional/normativa/ordenanza-230020-crease-comite-expertos-cientificos-gestion-crisis

22 Ministry of Public Health. Joint intra-action review of the public health response to covid-19 in Thailand. Ministry of Public Health, 2020

23 Wieler LH, Rexroth U, Gottschalk R. Emerging COVID-19 success story: Germany's push to maintain progress. 2021. https://ourworldindata.org/covid-exemplar-germany?country=

24 Whitmee S, Haines A, Beyrer C, etal. Safeguarding human health in the Anthropocene epoch: report of The Rockefeller Foundation-Lancet Commission on planetary health. Lancet 2015;386:1973-2028. . doi: 10.1016/S0140-6736(15)60901-1 pmid: 26188744

25 Watts N, Amann M, Arnell N, etal. The 2019 report of The Lancet Countdown on health and climate change: ensuring that the health of a child born today is not defined by a changing climate. Lancet 2019;394:1836-78. . doi: 10.1016/S0140-6736(19)32596-6 pmid: 31733928

26 Karliner J, Slotterback S, Boyd R, et al. Health care's climate footprint: Health Care Without Harm, Arup, 2019

27 Nilsson M, Ebi KL, Campbell-Lendrum D, Kone B, Friberg P. Covid-19-a rehearsal to build a greener and healthier society. BM/2021;372:n127. . doi: 10.1136/bmj.n127 pmid: 33509800

28 Rizan C, Reed M, Bhutta MF. Environmental impact of personal protective equipment distributed for use by health and social care services in England in the first six months of the COVID-19 pandemic. J R Soc Med 2021;114:250-63. doi: 10.1177/01410768211001583 pmid: 33726611

29 National Health Service. Delivering a 'net zero' national health service. National Health Service, 2020.

30 Bump JB, Baum F, Sakornsin M, Yates R, Hofman K. Political economy of covid-19: extractive, regressive, competitive. BMJ 2021;372:n73. doi: 10.1136/bmj.n73 pmid: 33483317

31 Razavi A, Erondu N, Okereke E. The Global Health Security Index: what value does it add?BMJ Glob Health 2020;5:e002477. doi: 10.1136/bmigh-2020-002477 pmid: 32349994

32 Abbey EJ, Khalifa BAA, Oduwole MO, etal. The Global Health Security Index is not predictive of coronavirus pandemic responses among Organization for Economic Cooperation and Development countries. PLoS One 2020;15:e0239398. doi: 10.1371/journal.pone.0239398 pmid: 33027257

33 Ravi SJ, Warmbrod KL, Mullen L, etal. The value proposition of the Global Health Security Index. BMJ Glob Health 2020;5:e003648. doi: 10.1136/bmigh-2020-003648 pmid: 33033053

34 Joseph J. Poverty reduction and the new global governmentality. Alternatives 2010;35:29-51. doi: $10.1177 / 030437541003500102$

35 Collier SJ, Ong A. Global Assemblages Anthropological Problems. In: Collier SJ, Ong A, eds. Global assemblages: technology, politics, and ethics as anthropological problems. Blackwell Publishing, 2007: 3-21doi: 10.1002/9780470696569.ch1

36 Ingram A. After the Exception: HIV/AIDS beyond salvation and scarcity. Antipode2013;45:436-54 doi: 10.1111/j.1467-8330.2012.01008.x.

37 Elbe S. AIDS, security, biopolitics. Int Relat 2005;19:403-19. doi: 10.1177/0047117805058532.

38 Fisher A. From diagnosing under-immunization to evaluating health care systems: immunization coverage indicators as a technology of global governance. In: Davis K, Fisher A, Kingsbury B, etal, eds. Governance by indicators: global power through quantification and rankings. 2012. 217-246. PUBLISHER??? doi: 10.1093/acprof:0so/9780199658244.003.0009

39 Davis KE, Kingsbury B, Merry SE. Indicators as a technology of global governance. Law Soc Rev 2012:46:71-104. doi: 10.1111/j.1540-5893.2012.00473.x.

40 Haldane V, De Foo C, Abdalla SM, etal. Health systems resilience in managing the COVID-19 pandemic: lessons from 28 countries. Nat Med 2021;27:964-80. doi: 10.1038/s41591-021-01381-y pmid: 34002090

41 World Health Organization. COVID-19 Solidarity Response Fund. 2021. https://www.who.int/emergencies/diseases/novel-coronavirus-2019/donate 
42 World Health Organization. "Solidarity" clinical trial for COVID-19 treatments. 2021. https://www.who.int/emergencies/diseases/novel-coronavirus-2019/global-research-on-novelcoronavirus-2019-ncov/solidarity-clinical-trial-for-covid-19-treatments

43 European Commission. European Commission emergency support instrument. 2021. https://ec.europa.eu/info/live-work-travel-eu/coronavirus-response/emergency-support-instrument_en\#general

44 European Commission. Humanitarian Aid: €64 million for most vulnerable in Southern Africa. 2020. https://ec.europa.eu/commission/presscorner/detail/en/ip_20_1374

45 European Commission. Coronavirus global response: EU Humanitarian Air Bridge to Peru and €30.5 million for Latin America and the Caribbean. 2020. https://ec.europa.eu/commission/presscorner/detail/en/ip_20_1590

46 Delegation of the European Union to ASEAN. EU and ASEAN launch "Southeast Asia Health Pandemic Response and Preparedness" project, 2021. https://eeas.europa.eu/delegations/association-southeast-asian-nations-asean/99404/eu-and-asean-launch-southeast-asia-health-pandemic-response-and-preparedness\%E2\%80\%9D-project_en

47 Lai L. Asean summit: Singapore calls for equitable, steady, affordable supply of Covid-19 vaccines to region. The Straits Times 2020 Nov 13.. https://www.straitstimes.com/singapore/aseansummit-singapore-calls-for-equitable-steady-affordable-supply-of-covid-19-vaccines

48 Association of Southeast Asian Nations. ASEAN health sector efforts in the prevention, detection and response to coronavirus disease 2019 (COVID-19). 2020. https://asean.org/?static_post=updates-asean-health-sector-efforts-combat-novel-coronavirus-covid-19

49 Centre for Disease Control. The Africa CDC was crucial in responding to the Covid-19 pandemic 2021. https://www.theafricareport.com/79586/the-africa-cdc-was-crucial-in-responding-to-thecovid-19-pandemic/

50 Obulutsa G. Africa secures 400 million more COVID-19 vaccine doses. Africanews 2021 Jan 28. https://www.reuters.com/article/us-health-coronavirus-africa-idUSKBN29X1CE

51 Organisation for Economic Co-operation and Development. COVID-19 spending helped to lift foreign aid to an all-time high in 2020 but more effort needed. 2021

https://www.oecd.org/newsroom/covid-19-spending-helped-to-lift-foreign-aid-to-an-all-timehigh-in-2020-but-more-effort-needed.htm

52 Peru News Agency. Germany donates equipment to improve COVID-19 healthcare for native communities. Andina2020 Oct 7. https://andina.pe/ingles/noticia-germany-donates-equipmentto-improve-covid19-healthcare-for-native-communities-816799.aspx

53 Reuters Staff. German military to send medical staff and equipment to Portugal. Reuters 2021 Jan 31. https://www.reuters.com/article/us-health-coronavirus-portugal-germany-idUSKBN2AOODL

54 Nienaber M. Germany will send oxygen, medical aid to India to help in COVID crisis. Reuters 2021 Apr 26. https://www.reuters.com/world/india/germany-will-send-oxygen-medical-aid-india-helpcovid-crisis-2021-04-26/

55 Kings J. Pivoting New Zealand's Aid Programme to respond to COVID-19. Devpolicy Blog, 8 May 2020. https://devpolicy.org/pivoting-new-zealands-aid-programme-to-respond-to-covid-1920200508-3/

56 African Union Commission. African Union Covid19 Response Fund to launch \$300m fundraising to help tackle the effects of COVID-19 in Africa. 2020. https://au.int/en/newsevents/20201016/african-union-au-covid19-response-fund-launch-300m-fundraising-help-tackle

57 Covax: How many Covid vaccines have the US and the other G7 countries pledged? BBC News 2021 Sep 23. https://www.bbc.co.uk/news/world-55795297

58 Ramchandani R, Kazatchkine M, Liu J, etal. Vaccines, therapeutics, and diagnostics for COVID-19: redesigning systems to improve pandemic response. BMJ 2021;375:e067488. doi: 10.1136/BMJ-2021-067488.

This is an Open Access article distributed under the terms of the Creative Commons Attribution IGO License (https://creativecommons.org/licenses/by-nc/3.0/igo/), which permits use, distribution, and reproduction for non-commercial purposes in any medium, provided the original work is properly cited. 